\title{
First report of Taenia ovis infection in Danish sheep (Ovis aries)
}

Petersen, Heidi Huus; AI-Sabi, Mohammad N.S. ; Larsen, Gitte; Jensen, Tim Kåre; Chriél, Mariann

Published in:

Veterinary Parasitology

Link to article, DOI:

10.1016/j.vetpar.2017.12.011

Publication date:

2018

Document Version

Peer reviewed version

Link back to DTU Orbit

Citation (APA):

Petersen, H. H., Al-Sabi, M. N. S., Larsen, G., Jensen, T. K., \& Chriél, M. (2018). First report of Taenia ovis infection in Danish sheep (Ovis aries). Veterinary Parasitology, 251, 3-6.

https://doi.org/10.1016/j.vetpar.2017.12.011

\section{General rights}

Copyright and moral rights for the publications made accessible in the public portal are retained by the authors and/or other copyright owners and it is a condition of accessing publications that users recognise and abide by the legal requirements associated with these rights.

- Users may download and print one copy of any publication from the public portal for the purpose of private study or research.

- You may not further distribute the material or use it for any profit-making activity or commercial gain

- You may freely distribute the URL identifying the publication in the public portal 


\section{Accepted Manuscript}

Title: First report of Taenia ovis infection in Danish sheep (Ovis aries)

Authors: Heidi H. Petersen, Mohammad N.S. Al-Sabi, Gitte Larsen, Tim K. Jensen, Mariann Chriél

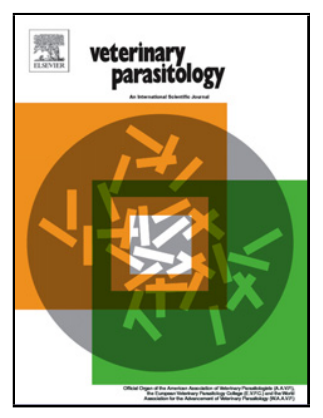
PII: $\quad$ S0304-4017(17)30517-4
DOI: $\quad$ https://doi.org/10.1016/j.vetpar.2017.12.011
Reference: $\quad$ VETPAR 8533

To appear in: $\quad$ Veterinary Parasitology

Received date: $\quad 7-11-2017$

Revised date: $\quad 11-12-2017$

Accepted date: $\quad$ 13-12-2017

Please cite this article as: Petersen, Heidi H., Al-Sabi, Mohammad N.S., Larsen, Gitte, Jensen, Tim K., Chriél, Mariann, First report of Taenia ovis infection in Danish sheep (Ovis aries).Veterinary Parasitology https://doi.org/10.1016/j.vetpar.2017.12.011

This is a PDF file of an unedited manuscript that has been accepted for publication. As a service to our customers we are providing this early version of the manuscript. The manuscript will undergo copyediting, typesetting, and review of the resulting proof before it is published in its final form. Please note that during the production process errors may be discovered which could affect the content, and all legal disclaimers that apply to the journal pertain. 


\title{
First report of Taenia ovis infection in Danish sheep (Ovis aries).
}

Heidi H. Petersen ${ }^{a^{*}}$, Mohammad N.S. Al-Sabi ${ }^{\mathrm{b}}$, Gitte Larsen ${ }^{\mathrm{a}}$, Tim K. Jensen ${ }^{\mathrm{a}}$ and Mariann Chriél ${ }^{\mathrm{a}}$

a Section for Diagnostics and Scientific Advice, National Veterinary Institute, Technical University of Denmark, Kemitorvet, 2800 Kgs. Lyngby, Denmark

${ }^{\mathrm{b}}$ Department of Pharmacology, Faculty pf Pharmacology, Al-Zaytoonah University of Jordan, Queen Alia Airport St. 594, Amman, P.O. Box: 11733, Jordan

\author{
${ }^{*}$ Corresponding author. \\ Address: Kemitorvet, DK-2800 Kgs. Lyngby \\ Tel.: +45935116 45; \\ E-mail address: hhpet@vet.dtu.dk
}




\section{Graphical abstract}

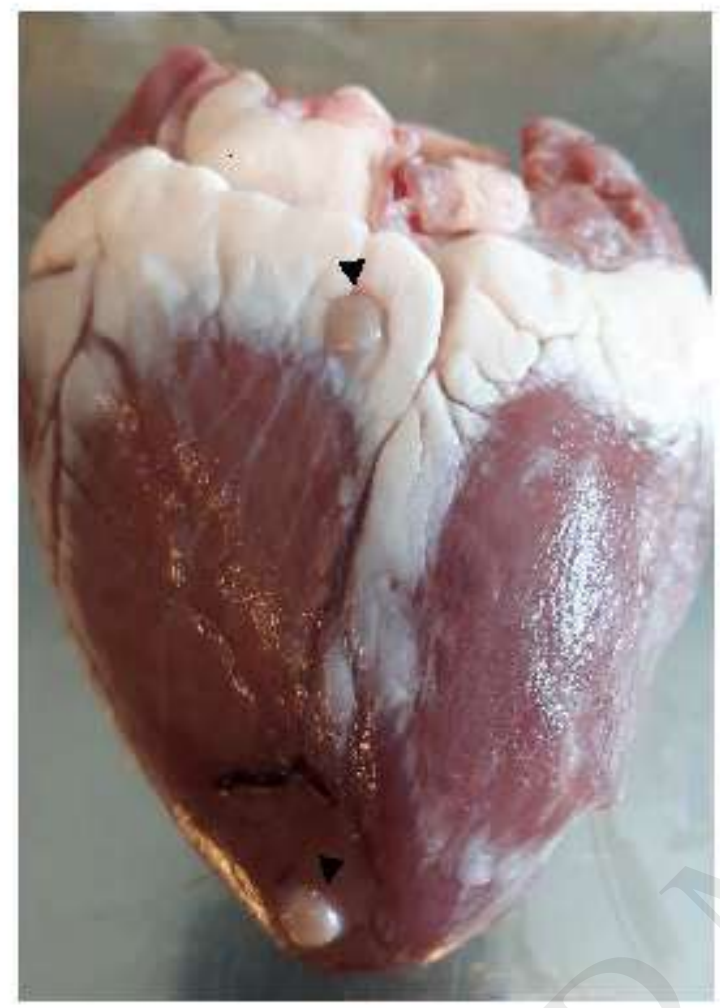

\section{Highlights}

- We identified the metocestode stage of Taenia ovis from domestic sheep in Denmark

- This is the first report of Taenia ovis infection in Danish sheep

- The Danish isolate was aggregated in one branch together with isolates from Asia

- This parasite was probably introduced to the farm by recently imported dogs 


\begin{abstract}
We report Taenia ovis infection in Danish sheep for the first time. In spring 2016, the metocestode stage of T. ovis was at slaughter observed in heart muscles, diaphragm and skeletal muscles from approx. a third of all sheep from one specific farm localised in South Jutland. The diagnosis was confirmed by molecular typing of the mitochondrial cytochrome c oxidase I (cox1) gene. Three newly imported dogs were suspected but the definitive host was unidentifiable. The finding is not regulated in the meat control procedures. However, infected meat is usually condemned due to aesthetic reasons causing economic losses. Thus, finding of $T$. ovis is of concern to sheep meat producers in the area, as the infection could have spread further on to other farms.
\end{abstract}

Keywords: Taenia ovis; Sheep measles; sheep; meat hygiene, intermediate host; Dogs; Cox1; Denmark

\title{
1. Introduction
}

Taenia ovis (also known as Cysticercus ovis or 'sheep measles') is a parasitic tapeworm belonging to the family Taeniidae. The adult stage resides in the small intestines of infected canids, including domestic dogs (Ransom, 1913) and red foxes (Vulpes vulpes) (Jenkins et al., 2014). The adult worms pass eggs onto pastures via faeces. Infestation in sheep (intermediate host) occurs when they inadvertently ingest the infective eggs when grazing on contaminated pasture. In intermediate hosts, the larval stage (also called metacestode stage or cysticerci) burrows through the intestinal mucosa and migrate via the bloodstream to the muscles. The predilection sites are cardiac muscles, diaphragm and masseter muscles. In heavy 
infestations the larvae can also be observed throughout the skeletal musculature (Arundel, 1972). The infective cysticerci appear as small (approximately $4-6 \mathrm{~mm}$ ) clear, cyst-like lesions in the muscles, each containing a single scolex (Arundel, 1972). Cysts are developed approx. two months following egg ingestion (Ransom, 1913), hereafter the cysts remain infective to canids for 1-2 months (Ransom, 1913). If raw cystholding meat is eaten by a canid, the adult parasite develops in the small intestine and the lifecycle continues. If the sheep is not slaughtered, the cysts calcify and form a small, innocuous nodule with a 'gritty' texture (DeWolf et al., 2014). This stage is commonly known as sheep measles due to the "spotty" appearance of meat containing the pale cystic lesions.

Taenia ovis infestations in sheep are of no apparent veterinary importance and in contrast to the other taeniid cestode, i.e. Echinococcus multilocularis and E. granulosus, canids infected with adult $T$. ovis pose no risk to human health. The importance of $T$. ovis is mainly of relevance to the meat industry is infestation in sheep with the intermediate stages of these cestodes leading to important financial losses, due to downgrading and condemnation of meat and hearts. Taenia ovis infestation is also a potential impediment to international trade of sheep meat (Jenkins et al., 2014). Both viable and calcified cysticerci are visible in the meat of infected animals, rendering it unacceptable for human consumption. The FAO guidelines recommend condemning of carcasses if lesions of $T$. ovis infestation are found in two of the usual inspection sites (masseter muscle, tongue, oesophagus, heart, diaphragm or exposed musculature).

Taenia ovis infestations appear worldwide, including Australia (Jenkins et al., 2014), Canada (DeWolf et al., 2014), China (Shi et al., 2016), England (Eichenberger et al., 2011), Ethiopia (Sissay et al., 2008), Iran (Hashemnia et al., 2016), Italy (Gori et al., 2015) and New Zealand (Lawson, 1994). Here we describe infestation with cysticerci of $T$. ovis in muscles of Danish sheep (Ovis aries). To our knowledge, this is the first publications describing this parasite infestation in Danish sheep. 


\section{Material and method}

\subsection{Case report}

In April 2016, a veterinarian observed approx. $5 \mathrm{~mm}$ whitish cysts-like nodules in the cardiac- and skeletal muscles of sheep and lambs during meat inspection at a small abattoir in the South Jutland, Denmark. According to the veterinarian, the cysts appeared in one-third of the animals from one particular farm during spring 2016. During summer, the number of cyst-positive animals decreased, and in winter 2017, none of the lambs born in the summer 2016 had cyst-like nodules, while some of the ewes had calcified nodules.

In May 2016, the National Veterinary institute, Technical University of Denmark (DTU-VET) received three hearts with the aforesaid cyst-like nodules from the abattoir. The cardiac muscles were examined grossly as samples were taken. For histology, samples of myocardium with cysts were fixed in $10 \%$ neutral buffered formalin. After fixation the samples were prepared by routine methods, embedded in paraffin wax and sectioned at 3-5 $\mu \mathrm{m}$. The sections were stained with haematoxylin and eosin for histopathological evaluation using a Leica DMRB microscope equipped with a MC120 HD camera and Leica Application Suite version 4.7.0, Leica Microsystems, Switzerland.

Cysts were dissected from the cardiac muscles and DNA of the cyst was extracted using QIAmp DNA mini kit according to the manufacturer's instructions (QIAmp DNA mini kit ${ }^{\circledR}$, Qiagen, Hilden, Germany). The mitochondrial cytochrome c oxidase subunit 1 gene (cox1) was amplified using general primers according to Bowles et al. (1992). PCR amplicons were sequenced in both directions using ABI Prism Big Dye Terminator v 3.1 Sequencing Kit (Applied Biosystems, Foster City, CA), and the sequence was analysed according to the description of the manufacturer of Genetic Analyzer 3130 (Applied Biosystems, Appiera, Denmark). The consensus cox-1 sequence determined here was subjected to BLASTn analysis. Related sequences were retrieved from Genbank ${ }^{\mathrm{TM}}$ and alignment for further sequence analysis. Sequences were compared with other cox1 sequences of Taenia spp. present in Genbank ${ }^{\mathrm{TM}}$ to evaluate sequence similarity, 
expressed as percentage of nucleotide identity. Phylogenetic relationships were inferred as described in AlSabi et al. (2013). Evolutionary relationships were inferred after constructing neighbourjoining (NJ) trees (Saitou and Nei, 1987), using the software MEGA6 (Tamura et al., 2013). Nucleotide sequence data reported in this paper are available in the GenBank ${ }^{T M}$ under the accession number MG59480.

\subsection{The sheep farm}

The sheep and lambs originated from a farm in Skærbæk, in the South Jutland, Denmark, approx. $40 \mathrm{~km}$ north of the German border. The affected farm consists of approx. 400 ewes, raising 500 lambs per year for meat producing. Among others, the meat was used to produce Biologically Appropriate Raw Foods (BARF) for pets. The farm is located in an area where recently migrated wolves are living. Wolves have reappeared in Denmark within the last few years after around 200 years of absence. To protect the sheep from wolves, the sheep farmer imported three Maremmano Abruzzese puppies from Italy and Polen in June - December 2014, respectively. The farmer housed two other breeds: border collies and a labrador retriever. Both have access to the pastures where sheep are grazing, while the Maremmano Abruzzese lives together with the sheep. The dogs have been fed raw sheep meat originating from the farm. As the farm is located in known E. multilocularis risk area, all farm dogs are given anthelminthic treatment every second month. The Maremmano Abruzzese dogs were not dewormed prior to or upon arrival to Denmark, but entered straight into the treatment program at the farm.

Upon observation of cysts in the sheep, faeces from the three Maremmano Abruzzese dogs were analysed using a modified McMaster technique (Roepstorff and Nansen, 1998) at DTU-VET to reveal the presence of Taenia eggs, the analysis were however, after the dogs was dewormed.

\section{Results and Discussion}

The three hearts from sheep forwarded to DTU-VET contained 1-5 white cyst-like nodules of approx. $5 \mathrm{~mm}$ in diameter (Fig. 1). As the cysts only contained a pastious white material and/or were calcified, diagnosing 
the parasite based on metacestode morphology was not possible. Histopathologically, the examined nodules were organized as abscesses containing eosinophilic masses of detritus and mineralized granules without clear signs of neither encapsulation or presence of vital parasites, as shown in Fig. 2a. However, a few eosinophilic structures resembling cross sections of necrotic helminths/cysticerci were observed (Fig $2 b)$. The wall of the abscesses was relatively thin consisted of layers of mononuclear cells and fibrocytes. No inflammatory reaction was observed in the adjacent myocardium.

Based on the molecular analysis, the isolated cysts were identified as the cysticerci of $T$. ovis. This is the first published report of this parasite in Denmark, and no documentation on its previous presence is, to our knowledge, available.

Initially, the imported Maremmano Abruzzese dogs were considered the possible source, since the dogs were recently introduced on the farm and might have hosted the parasite prior to entering Denmark. The dogs had access to the sheep pasture and the possibility to contaminate the pastures with eggs. However, all farm dogs tested negative for taeniid eggs, but the dogs were treated with anthelminthic prior to examination. Thus, the pasture contamination could have occurred prior to treatment and testing.

Difference in nucleotide composition (390 bp) between Danish isolates and other isolates of $T$. ovis ranged 0.0 to $0.08 \%$. Based in Phylogenetic analysis, the Danish isolates were aggregated in one branch together with isolates from Asia.

In this report, T. ovis infestation appeared as an isolated incident, which seemingly arose from import of infected dogs. Moreover, the lambs born in 2016 were free of cysts, indicating that the contamination is no longer present at the pastures. However, based on experimental studies, T. ovis eggs can remain viable on pasture for at least 300 days (Arundel, 1979). Single adult worm may produce $70,000-250,000$ eggs per day (DeWolf et al., 2014), posing a risk for pasture contamination. However, pasture rotation might prevent reinfection on farms. 
This current finding of $T$. ovis is of particular concern for this farm, as the meat is sold for raw consumption as lamb tatar to humans and BARF food for pets. Infested meat is usually considered inappropriate for human consumption (Rehbein et al., 2000), although the ovine muscular cystic lesions caused by $T$. ovis do not cause infection in humans, but are aesthetically undesirable in meat destined for human consumption.

Currently, there are no practical options for the treatment of the intermediate host. However, control measures include regular anthelmintic treatments of the farm dogs and omit feeding dogs with raw contaminated muscles or organs. Though, freezing the sheep meat and hearts for 10 days will inactivate $T$. ovis cystercerci rendering the meat safe to feed to dogs.

Although domestic dogs are considered the main definitive host for $T$. ovis, other canids has been proposed as potential definitive hosts, including wolves (Moks et al., 2006) and red foxes (Jenkins et al., 2014). In these publications, cestode identification was based on morphology, a method unusable when distinguishing between $T$. krabbei and T. ovis. The wolf is well-documented as final host for T. krabbei (Bryan et al., 2012; Craig and Craig, 2005; Holmes and Podesta, 1968). Since T. krabbei and T. ovis are morphological undifferentiable, morphological diagnosis of these parasites may be incorrect. However, in recent studies from Australia and Italy, molecular analysis have documented red foxes (Vulpes vulpes) (Jenkins et al., 2014) and wolves as sylvatic definitive host of $T$. ovis (Gori et al., 2015). Therefore, Danish wildlife could have been the source of the $T$. ovis infestation. However, the spread of $T$. ovis to wildlife like red foxes are less likely, since raw meat from production animals are not available to wildlife due to current legislation. In conclusion, although the definitive host was unidentifiable, is was suspected that to be three newly imported dogs, although there is a possibility that wild canid species, which has recently invaded Denmark was the source. 


\section{Acknowledgement}

The slaughterhouse and the veterinarians Inga Stamphøj and Randi Worm are acknowledged for collecting and forwarding the samples that contained the parasite cyst. Laboratory technicians Boi-tien Thi Pham and Aleksandra Tofteby are thanked for technical assistance. The work was financed by Technical University of Denmark, National Veterinary Institute.

\section{References}

Al-Sabi, M.N.S., Chriél, M., Holm, E., Jensen, T.K., Ståhl, M., Enemark, H.L., 2013. Reappearance of Taenia ovis krabbei muscle cysts in a roe deer (Capreolus capreolus) in Denmark after 60+ years, Veterinary Parasitology. doi:10.1016/j.vetpar.2012.12.044

Arundel, J.H., 1979. Hydatid disease of animals in Australia. Aust. Vet. J. 55, 126-130. doi:10.1111/j.17510813.1979.tb15248.x

Arundel, J.H., 1972. A review of cysticercoses of sheep and cattle in Australia. Aust. Vet. J. 48, 140-155. doi:10.1111/j.1751-0813.1972.tb09262.x

Bowles, J., Blair, D., McManus, D.P., 1992. Genetic variants within the genus Echinococcus identified by mitochondrial DNA sequencing. Mol. Biochem. Parasitol. 54, 165-73.

Bryan, H.M., Darimont, C.T., Hill, J.E., Paquet, P.C., Thompson, R.C.A., Wagner, B., Smits, J.E.G., 2012. Seasonal and biogeographical patterns of gastrointestinal parasites in large carnivores: wolves in a coastal archipelago. Parasitology 139, 781-790. doi:10.1017/S0031182011002319

Craig, H.L., Craig, P.S., 2005. Helminth parasites of wolves (Canis lupus): a species list and an analysis of published prevalence studies in Nearctic and Palaearctic populations. J. Helminthol. 79, 95-103. 
DeWolf, B., Peregrine, A., Jones-Bitton, A., Jansen, J., Menzies, P., 2014. Taenia ovis infection and its control: a Canadian perspective. N. Z. Vet. J. 62, 1-7. doi:10.1080/00480169.2013.832109

Eichenberger, R.M., Karvountzis, S., Ziadinov, I., Deplazes, P., 2011. Severe Taenia ovis outbreak in a sheep flock in south-west England. Vet. Rec. 168, 619. doi:10.1136/vr.d887

Gori, F., Armua-Fernandez, M.T., Milanesi, P., Serafini, M., Magi, M., Deplazes, P., Macchioni, F., 2015. The occurrence of taeniids of wolves in Liguria (northern Italy). Int. J. Parasitol. Parasites Wildl. 4, 252-255. doi:10.1016/j.jppaw.2015.04.005

Hashemnia, M., shahbazi, Y., Frajani Kish, G., 2016. Prevalence and pathological lesions of ovine cysticercosis in slaughtered sheep in western Iran. J. Parasit. Dis. 40, 1575-1578. doi:10.1007/s12639015-0732-7

Holmes, J.C., Podesta, R., 1968. The helminths of wolves and coyotes from the forested regions of Alberta. Can. J. Zool. 46, 1193-1204.

Jenkins, D.J., Urwin, N.A.R., Williams, T.M., Mitchell, K.L., Lievaart, J.J., Armua-Fernandez, M.T., 2014. Red foxes (Vulpes vulpes) and wild dogs (dingoes (Canis lupus dingo) and dingo/domestic dog hybrids), as sylvatic hosts for Australian Taenia hydatigena and Taenia ovis. Int. J. Parasitol. Parasites Wildl. 3, 7580. doi:10.1016/j.ijppaw.2014.03.001

Lawson, J.R., 1994. Hydatid disease and sheep measles: The history of their control and the economics of a recent change of control policy. New Zeal. J. Zool. 21, 83-89. doi:10.1080/03014223.1994.9517978

Moks, E., Jõgisalu, I., Saarma, U., Talvik, H., Järvis, T., Valdmann, H., 2006. Helminthologic survey of the wolf (Canis lupus) in Estonia, with an emphasis on Echinococcus granulosus. J. Wildl. Dis. 42, 359-365. doi:10.7589/0090-3558-42.2.359

Ransom, B.H., 1913. Cysticercus ovis, the cause of tapeworm cysts in mutton. J. Agric. Res. 1, 15-58. 
Roepstorff, A., Nansen, P., 1998. Epidemiology, diagnosis and control of helminth parasites of swine. FAO animal health manual, Rome.

Saitou, N., Nei, M., 1987. The neighbor-joining method: a new method for reconstructing phylogenetic trees. Mol. Biol. Evol. 4, 406-25.

Shi, W., He, W., Guo, X., Liu, Q., Gao, S., Zhan, F., Liu, X., Pan, Y., Luo, X., Zheng, Y., 2016. The first outbreak of Taenia ovis infection in China. Parasitol. Int. 65, 422-423. doi:10.1016/j.parint.2016.06.005

Sissay, M.M., Uggla, A., Waller, P.J., 2008. Prevalence and seasonal incidence of larval and adult cestode infections of sheep and goats in eastern Ethiopia. Trop. Anim. Health Prod. 40, 387-394. doi:10.1007/s11250-007-9096-z

Tamura, K., Stecher, G., Peterson, D., Filipski, A., Kumar, S., 2013. MEGA6: Molecular Evolutionary Genetics Analysis Version 6.0. Mol. Biol. Evol. 30, 2725-2729. doi:10.1093/molbev/mst197

\section{Figure captions}

Figure 1: Taenia ovis cysticerci in the cardiac mucle from sheep (sheep measles).

Figure 2: Heart muscle from a slaughtered sheep with a subpicardial cyst-like nodule. The nodule is organized as an abscess containing eosinophilic masses of detritus and mineralized granules (arrow). a) The wall of the abscess (arrow head) is relatively thin consisting of a few layers of mononuclear cells and fibrocytes. No inflammatory reaction was observed in the adjacent myocardium (star). H\&E, bar $1 \mathrm{~mm}$. An eosinophilic structure similar to a cross section of necrotic helminth/cysticerci with a homogeneous cuticle (arrow head) is seen in the centre of the abscess (square). b) H\&E, bar $200 \mu \mathrm{m}$. 
Figure 3: Phylogenetic tree inferring the evolutionary relationship between a Danish isolate of Taenia ovis with other T. ovis isolates worldwide, and two closely related Taenia species as out-groups. The tree was inferred using the Neighborjoining method, based on analysis of $390 \mathrm{bp}$ of the mitochondrial cox-1 gene. The scale bar indicates distance.
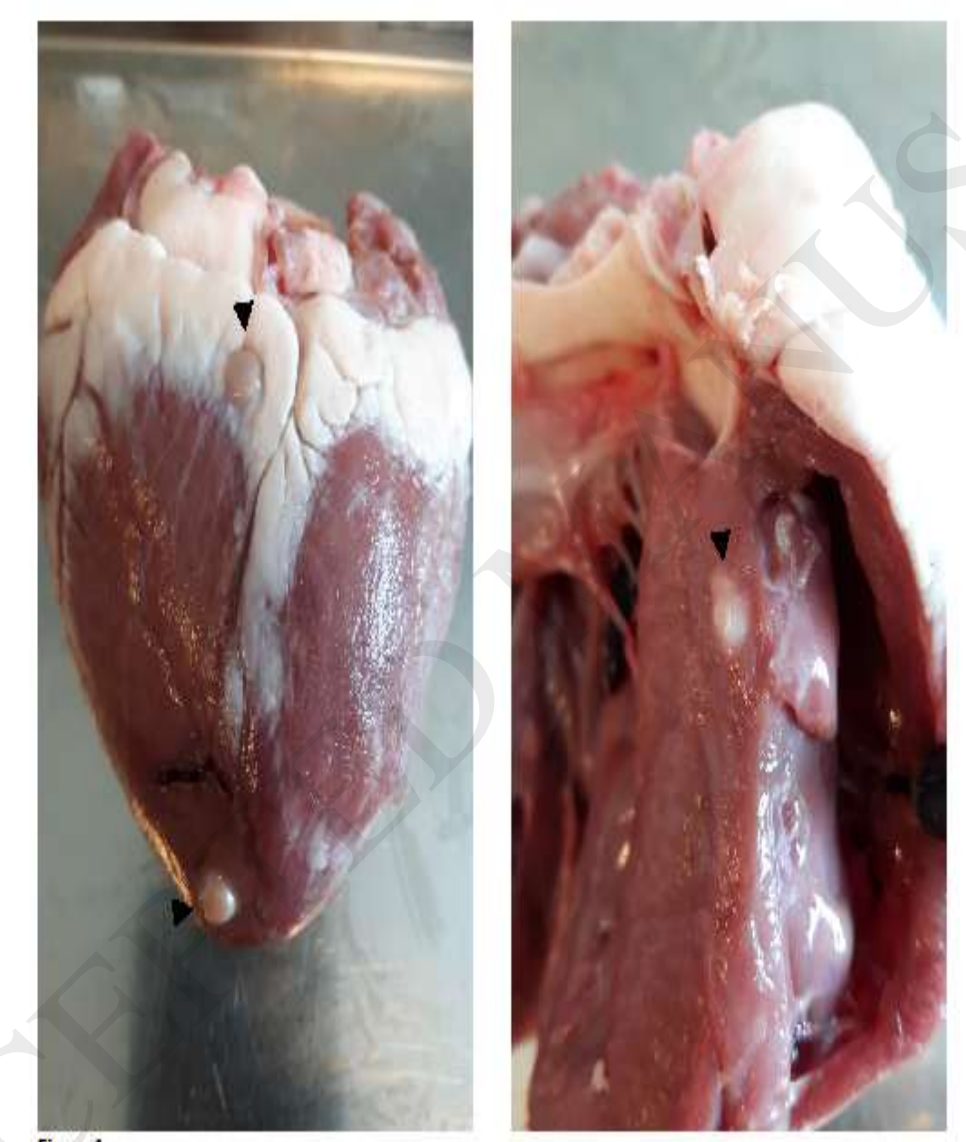

Figure1 

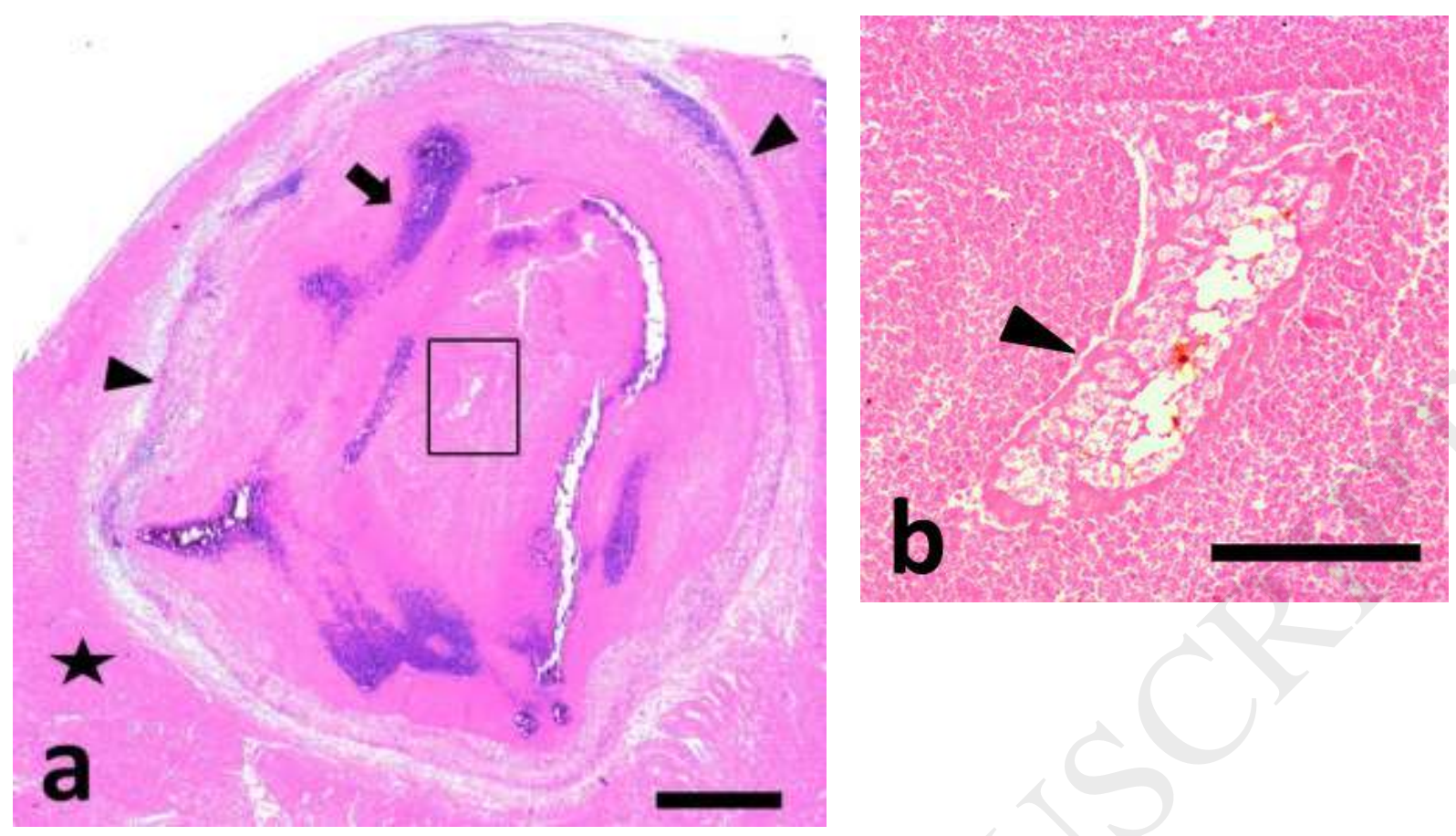

Figure 2:

Figure 3

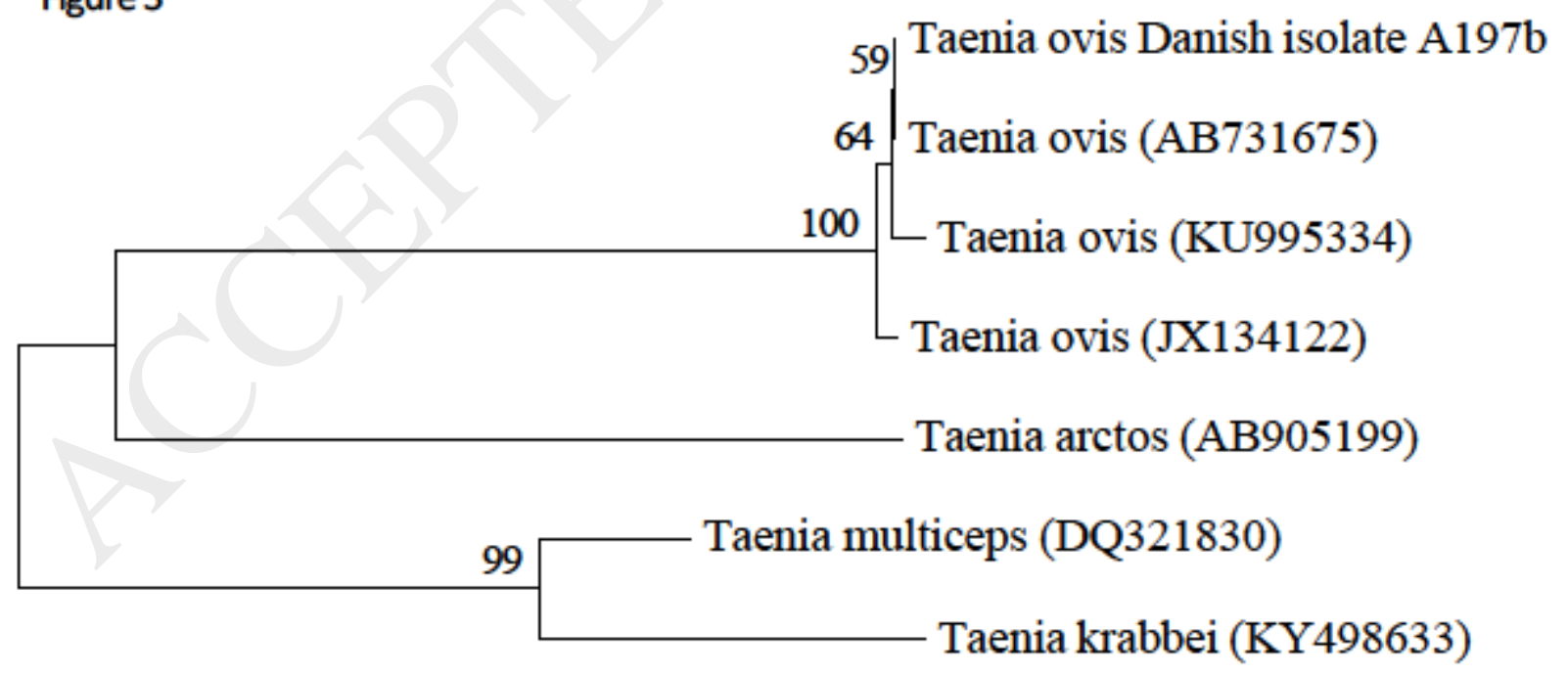

